\title{
Depressive Symptoms Are Associated with More Hopelessness among White than Black Older Adults
}

\author{
Shervin Assari ${ }^{1,2 *}$ and Maryam Moghani Lankarani ${ }^{3}$ \\ 'Department of Psychiatry, University of Michigan, Ann Arbor, MI, USA, ${ }^{2}$ Center for Research on Ethnicity, Culture and \\ Health (CRECH), School of Public Health, University of Michigan, Ann Arbor, MI, USA, ${ }^{3}$ Medicine and Health Promotion \\ Institute, Tehran, Iran
}

Background: Hopelessness is a core component of depression. Our information is, however, very limited on ethnic variations in the magnitude of the link between depression and hopelessness. Using a national sample of older adults in United States, we compared Blacks and Whites for the magnitude of the association between depressive symptoms and hopelessness.

Methods: With a cross-sectional design, we used baseline data of the Religion, Aging, and Health Survey, 2001. Linear regression models were used for data analysis.

OPEN ACCESS

Edited by:

Haichang Xin,

University of Alabama at

Birmingham, USA

Reviewed by:

Gianluca Serafini,

University of Genoa, Italy

Yingchen Wang,

University of North Carolina-

Greensboro, USA

*Correspondence:

Shervin Assari

assari@umich.edu

Specialty section: This article was submitted

to Epidemiology,

a section of the journal

Frontiers in Public Health

Received: 12 February 2016

Accepted: 15 April 2016

Published: 04 May 2016

Citation:

Assari S and Lankarani MM (2016)

Depressive Symptoms Are

Associated with More Hopelessness

among White than

Black Older Adults.

Front. Public Health 4:82.

doi: 10.3389/fpubh.2016.00082
Depressive symptoms (CES-D) and hopelessness were conceptualized as independent and dependent variables in different models, respectively. Demographic factors (age and gender), socioeconomic status (education and marital status), and health (self-rated health) were covariates. Ethnicity was the moderator.

Results: In the pooled sample, higher depressive symptoms were predictive of hopelessness, above and beyond all covariates. We also found significant interactions suggesting that the association between depressive symptoms and hopelessness is weaker among Blacks compared to Whites. In ethnic-specific models, there were significant associations between depressive symptoms and hopelessness among Whites but not Blacks.

Conclusion: Depressive symptoms accompany more hopelessness among Whites than Blacks. This finding may explain why Blacks with depression have a lower tendency to commit suicide. Future research should test whether or not Whites with depression better respond to psychotherapies and cognitive behavioral therapies that focus on hope enhancement. This finding may explain differential correlates of depression based on race and ethnicity.

Keywords: ethic groups, race, ethnicity, depression, depressive symptoms, hopelessness

\section{INTRODUCTION}

Hopelessness is associated with a wide range of negative mood states, both in the general population and clinical settings (1). Hopelessness increases the risk of emotional maladjustment (2). The literature has consistently shown that hopelessness is a risk factor for depression (3). Individuals with depression experience higher levels of hopelessness than those without depression (4-6). Whether or not ethnic groups differ in the link between depression and hopelessness is, however, unknown. 
Negative perspectives concerning the future, which is hopelessness, is a part of Beck's negative cognitive triad (7). Hopelessness is a main aspect of a depressive cognitive style (7). As described by Beck, hopelessness plays a key role in the trajectory of depression and suicide, and it has been confirmed as a risk factor for negative outcomes associated with depression $(8,9)$. Both retrospective and large-scale prospective follow-up studies have documented hopelessness as a strong predictor of suicidal behavior $(10,11)$. Hopelessness also predicts general mood outcomes and functioning in the presence of affective disorders (12).

Ethnicity influences how hopelessness (13) and depression (14) are distributed across populations. Studies have shown that hope and optimism are differently experienced across ethnic groups, who are different in cultural experiences, life circumstances, values, and beliefs (15-17). Hirsch et al. studied depressive symptoms, hopelessness [defined as future attitudes and motivation loss (pathways)], trait hope [defined as confidence in the ability to identify and attain goals (agency)], and suicidal behaviors among Whites and Blacks. Trait hope buffered the association between low depressive symptoms and suicidal behavior for Whites but not Blacks. In addition, while hope remained a significant moderator for Whites, hopelessness operated as the main buffer for Blacks. The study suggested that outcomes associated with hope and hopelessness differ based on ethnicity (13).

Differential effect hypothesis views ethnicity not only as a proxy of exposure to risk and protective factors but also as a contextual factor that shapes human's resilience and vulnerability. Based on this view, ethnicity operates as a contextual factor and alters how the very same risk and protective factors influence the very same health outcomes across diverse populations (18-25). This view is very different from the traditionally used differential exposure hypothesis, which attributes disparities in outcomes to group differences in exposures rather than vulnerabilities. Distinct from the differential exposure hypothesis, which assumes universality of the effects of risk and resilience factors, the differential effect hypothesis is focused on heterogeneity in the magnitude and direction of the effects that ultimately shape health and illness of diverse populations. Thus, instead of merely focusing on the main effect of ethnicity on exposures and outcomes or testing mediating effects of exposure, the differential effect hypothesis searches for qualitative and quantitative differences in the magnitude and direction of the associations between predictors and outcomes (26). According to the differential effect hypothesis, associations in health are seldom universal but specific to context (22-26).

Using a national sample of older adults in the United States and built on previous studies in the field (13) $)^{1,2}$ the current study tests the moderating effect of ethnicity on the association between depressive symptoms and hopelessness. Based on previous theoretical work (27-29) and empirical evidence (1-6) on hopelessness and depression, we expected a weaker association between depressive symptoms and hopelessness for Blacks compared to

\footnotetext{
${ }^{1}$ Assari S, Dejman M. Heterogeneity of the depression - self-esteem association based on race and gender. Front Psychol (2016).

${ }^{2}$ Assari S. Link between depressive symptoms and self-evaluation stronger among Blacks than Whites. Front Hum Neurosci (2016).
}

Whites, given their higher levels of religiosity (30-32), connectedness (33), and social support (34). This study contributes to the literature as - up to our knowledge - very limited information exists on group differences in the association between depression and hopelessness.

\section{MATERIALS AND METHODS}

\section{Design and Setting}

This cross-sectional study used baseline data of the religion, aging, and health survey, a household survey, 2001. The study protocol received Institutional Review Board (IRB) approval from University of Michigan. All participants provided consent (35).

\section{Sampling and Participants}

The study is limited to White or Black American older adults. All participants were non-institutionalized English speaking people of age more than 65 years. The study population was limited to Christians or those who were never associated with any faith. Older Blacks were oversampled in the survey (35).

\section{Measures}

Ethnicity, age, gender, education, marital status, self-rated health (SRH), depressive symptoms, and hopelessness were measured via face-to-face interviews in 2001.

\section{Depressive Symptoms}

An eight-item Center for Epidemiological Studies-Depression scale (CES-D) (36) was used to measure depressive symptoms. Items used were as the following: (1) felt I could not shake off the blues even with the help of my family and friends, (2) I felt depressed, (3) I had crying spells, (4) I felt sad, (5) I did not feel like eating, my appetite was poor, (6) I felt that everything I did was an effort, (7) My sleep was restless, and (8) I could not get going. All these items either measure negative affect or somatic symptoms. Positive affect and interpersonal items were not reflected in this version of the CES-D. Abbreviated CES-D measures using 8 items $(37,38)$ have shown acceptable reliability and validity as compared to the original 20 -item version $(27,39,40)$. Responses ranged from 1 ("rarely or none") to 4 ("most or all of the time"). We calculated mean score which was treated as a continuous measure, with a potential range from 1 to 4 . Higher scores indicated more depressive symptoms (Alpha $=0.870$ for all, 0.849 for Whites, 0.889 for Blacks).

\section{Hopelessness}

Hopelessness was measured with the following four items: (1) I always look on the bright side of things, (2) I am optimistic about my future, (3) In uncertain times, I always expect the best, and (4) I feel confident that the rest of my life will turn out well. These items are based on the scales developed by Scheier and Carver (3) and Krause (41). Item responses included strongly agree (1), agree (2), disagree (3), and strongly disagree (4). We did not use any specific cut-off score. Instead, we operationalized hopelessness as a continuous measure. We calculated our hopelessness score as the mean of the four items, where a higher 
score reflected more hopelessness (less hope) (42) (Alpha $=0.896$ for all, 0.892 for Whites, 0.901 for Blacks).

\section{Self-Rated Health}

Individuals were evaluated for their SRH in 2001 using the following single item: how would you rate your overall health at the present time? Would you say your health is excellent, good, fair, or poor? Response options included excellent (1), good (2), fair (3), or poor (4). SRH has shown high reliability and validity. We operationalized SRH as a dichotomous variable comparing poor vs. other statuses. Dichotomization of a continuous (ordinal) variable will result in loss of information; however, SRH has been widely treated as a dichotomous variable in the literature (43-45). Operationalizing SRH as a dichotomous variable increases the degrees of freedom in our models.

\section{Statistical Analysis}

We used SPSS 20.0 for Windows (IBM Inc., Armonk, NY, USA) for data analysis. For bivariate analysis, we used Pearson correlation test. For multivariable analysis, linear regression was applied. To test the reciprocal associations between depressive symptoms, once we considered depressive symptoms as an independent variable and hopelessness as the outcome, then we ran linear regressions with hopelessness as the independent variable and level of depressive symptoms as the outcome. In the first step, we fitted linear regressions in the pooled sample (Model 1). Then, we added the interaction term (Model 2), which was the multiplication of ethnicity ( 0 for Whites 1 for Blacks) and depressive symptoms or hopelessness (treated as a continuous measure). In the next step, we ran ethnic-specific models (Model 4 and Model 5). In all our models, demographics, socioeconomics, and SRH were covariates, and ethnicity was the moderator. Adjusted correlation coefficients ( $\beta$ ), SE, and 95\% Confidence Intervals (CI) were reported. $p$-Values $<0.05$ were considered statistically significant.

\section{RESULTS}

Table 1 presents descriptive statistics, overall and also based on race. While age was not significantly different between Blacks and Whites $(74.91 \pm 6.49$ vs. $75.37 \pm 6.82, p>0.05)$, Blacks were more likely to be female ( 65.1 vs. $58.6 \%, p<0.05$ ), had lower education ( 44.0 vs. $73.4 \%, p<0.05$ ), were less frequently married (35.7 vs. 59.5\%, $p<0.05$ ), and reported worse selfrated health ( 15.1 vs. $8.2 \%, p<0.05)$ (for all comparisons). Blacks had marginally significant higher depressive symptoms $(1.59 \pm 0.65$ vs. $1.54 \pm 0.59, p=0.06)$. Hopelessness was not different between Blacks and Whites $(1.82 \pm 0.60$ vs. $1.91 \pm 0.58$, $p>0.05)$.

Table 2 shows the results of correlations between study variables in the pooled sample as well as ethnic groups. Based on this table, depressive symptoms and hopelessness were positively correlated in the pooled sample $(r=0.151$, $p<0.001)$. Depressive symptoms and hopelessness were correlated among Whites $(r=0.227, p<0.001)$ but not Blacks $(r=0.080, p>0.05)$.
TABLE 1 | Descriptive statistics in the pooled sample and based on ethnicity.

\begin{tabular}{|c|c|c|c|c|c|c|}
\hline & \multicolumn{2}{|c|}{ All } & \multicolumn{2}{|c|}{ Whites } & \multicolumn{2}{|c|}{ Blacks } \\
\hline & Mean & SD & Mean & SD & Mean & SD \\
\hline Age & 75.14 & 6.66 & 75.37 & 6.82 & 74.91 & 6.49 \\
\hline $\begin{array}{l}\text { Depressive } \\
\text { symptoms }\end{array}$ & 1.57 & 0.62 & 1.54 & 0.59 & 1.59 & 0.65 \\
\hline Hopelessness & 1.87 & 0.59 & 1.91 & 0.58 & 1.82 & 0.60 \\
\hline \multirow{2}{*}{$\begin{array}{l}\text { Self-rated health } \\
\text { (poor) }{ }^{\star}\end{array}$} & 1.55 & 0.64 & 1.53 & 0.65 & 1.58 & 0.63 \\
\hline & $n$ & $\%$ & $n$ & $\%$ & $n$ & $\%$ \\
\hline \multicolumn{7}{|l|}{ Gender* } \\
\hline Male & 570 & 38.2 & 314 & 41.4 & 256 & 34.9 \\
\hline Female & 923 & 61.8 & 445 & 58.6 & 478 & 65.1 \\
\hline \multicolumn{7}{|l|}{$\begin{array}{l}\text { Education (high } \\
\text { school diploma)* }\end{array}$} \\
\hline Yes & 872 & 59.0 & 552 & 73.4 & 320 & 44.0 \\
\hline No & 607 & 41.0 & 200 & 26.6 & 407 & 56.0 \\
\hline \multicolumn{7}{|l|}{$\begin{array}{l}\text { Marital status } \\
(\text { married })^{\star}\end{array}$} \\
\hline No & 773 & 52.2 & 306 & 40.5 & 467 & 64.3 \\
\hline Yes & 708 & 47.8 & 449 & 59.5 & 259 & 35.7 \\
\hline \multicolumn{7}{|l|}{ Self-rated health* } \\
\hline $\begin{array}{l}\text { Fair, good, or } \\
\text { excellent }\end{array}$ & 1316 & 88.4 & 694 & 91.8 & 622 & 84.7 \\
\hline Poor & 173 & 11.6 & 62 & 8.2 & 111 & 15.1 \\
\hline
\end{tabular}

\section{Effect of Depressive Symptoms on Hopelessness}

Table 3 shows the results of four linear regressions with depressive symptoms as the independent and hopelessness as the dependent variable. Model 1 and Model 2 are run in the pooled sample, Model 3 was run among Whites, and Model 4 among Blacks. Model 1, which did not include any interaction, showed a positive association between depressive symptoms and hopelessness $(\beta=0.12,95 \%$ $\mathrm{CI}=0.33-1.17)$, net of all covariates. Model 2 showed a significant interaction between ethnicity and depressive symptoms on hopelessness ( $\beta=-0.25,95 \% \mathrm{CI}=-1.83$ to 0.22 , for the interaction term), suggesting a larger effect for Whites compared to Blacks. This interaction was significant net of all covariates. According to Model 3, depressive symptoms were positively associated with hopelessness among Whites $(\beta=0.20,95 \% \mathrm{CI}=0.72-1.93)$. Depressive symptoms were not associated with hopelessness among Blacks $(\beta=0.04,95 \% \mathrm{CI}=-0.39$ to 0.81$)$ (Model 4$)$.

\section{Effect of Hopelessness on Depressive Symptoms}

Table 4 shows the results of four linear regression models with hopelessness and depressive symptoms as the independent and dependent variables, respectively. The first two linear regressions are in the pooled sample, the third model is among Whites, and the fourth model is among Blacks. Model 1, which did not include the interaction term, showed hopelessness is positively associated with depressive 
TABLE 2 | Bivariate correlation matrix in the pooled sample and based on ethnicity.

\begin{tabular}{|c|c|c|c|c|c|c|c|c|}
\hline & 1 & 2 & 3 & 4 & 5 & 6 & 7 & 8 \\
\hline \multicolumn{9}{|l|}{ All } \\
\hline 1 Ethnicity (Blacks) & 1 & -0.034 & $0.067^{\star \star}$ & $-0.299^{\star \star}$ & $-0.238^{\star \star}$ & $0.108^{\star \star}$ & 0.048 & -0.006 \\
\hline 2 Age & & 1 & 0.023 & $-0.109^{\star \star}$ & $-0.177^{\star \star}$ & $0.107^{\star \star}$ & 0.027 & 0.061 \\
\hline 3 Gender (women) & & & 1 & -0.039 & $-0.321^{\star \star}$ & 0.019 & $0.084^{\star \star}$ & 0.046 \\
\hline 4 Education (high school diploma) & & & & 1 & $0.170^{\star \star}$ & $-0.164^{\star *}$ & $-0.150^{\star \star}$ & -0.049 \\
\hline 5 Marital status (married) & & & & & 1 & $-0.078^{\star \star}$ & $-0.120^{\star \star}$ & -0.047 \\
\hline 6 Self-rated health (poor) & & & & & & 1 & $0.300^{\star \star}$ & $0.142^{\star *}$ \\
\hline 7 Depressive symptoms & & & & & & & 1 & $0.151^{\star *}$ \\
\hline 8 Hopelessness & & & & & & & & 1 \\
\hline \multicolumn{9}{|l|}{ Whites } \\
\hline 1 Ethnicity (Blacks) & - & - & - & - & - & - & - & - \\
\hline 2 Age & & 1 & $0.081^{*}$ & $-0.126^{\star \star}$ & $-0.237^{\star \star}$ & $0.136^{\star \star}$ & $0.078^{\star}$ & 0.087 \\
\hline 3 Gender (women) & & & 1 & -0.067 & $-0.317^{\star \star}$ & 0.036 & $0.101^{\star \star}$ & 0.042 \\
\hline 4 Education (high school diploma) & & & & 1 & $0.154^{\star \star}$ & $-0.125^{\star \star}$ & $-0.175^{\star \star}$ & -0.034 \\
\hline 5 Marital status (married) & & & & & 1 & -0.067 & $-0.146^{\star \star}$ & -0.079 \\
\hline 6 Self-rated health (poor) & & & & & & 1 & $0.267^{\star \star}$ & $0.131^{\star \star}$ \\
\hline 7 Depressive symptoms & & & & & & & 1 & $0.227^{\star \star}$ \\
\hline 8 Hopelessness & & & & & & & & 1 \\
\hline \multicolumn{9}{|l|}{ Blacks } \\
\hline 1 Ethnicity (Blacks) & - & - & - & - & - & - & - & - \\
\hline 2 Age & & 1 & -0.029 & $-0.124^{\star \star}$ & $-0.144^{\star \star}$ & $0.086^{\star}$ & -0.013 & 0.040 \\
\hline 3 Gender (women) & & & 1 & 0.020 & $-0.315^{\star \star}$ & -0.002 & 0.059 & 0.052 \\
\hline 4 Education (high school diploma) & & & & 1 & 0.067 & $-0.151^{\star \star}$ & $-0.116^{\star \star}$ & -0.076 \\
\hline 5 Marital status (married) & & & & & 1 & -0.042 & $-0.082^{\star}$ & -0.013 \\
\hline 6 Self-rated health (poor) & & & & & & 1 & $0.324^{\star \star}$ & $0.157^{\star \star}$ \\
\hline 7 Depressive symptoms & & & & & & & 1 & 0.080 \\
\hline 8 Hopelessness & & & & & & & & 1 \\
\hline
\end{tabular}

${ }^{*} p<0.05$.

${ }^{* *} p<0.01$

TABLE 3 | Summary of the linear regressions for the association between depressive symptoms (independent variable) and hopelessness (dependent variable) in the pooled sample and based on race.

\begin{tabular}{|c|c|c|c|c|c|c|c|c|}
\hline & $\beta$ (SE) & $95 \% \mathrm{Cl}$ & $\beta$ (SE) & $95 \% \mathrm{Cl}$ & $\beta$ (SE) & $95 \% \mathrm{Cl}$ & $\beta$ (SE) & $95 \% \mathrm{Cl}$ \\
\hline & \multicolumn{2}{|c|}{$\begin{array}{c}\text { Model } 1 \\
\text { Main effect }\end{array}$} & \multicolumn{2}{|c|}{$\begin{array}{c}\text { Model } 2 \\
\text { With interaction }\end{array}$} & \multicolumn{2}{|c|}{ Model 3} & \multicolumn{2}{|c|}{ Model 4} \\
\hline Race (Blacks) & $-0.04(0.26)$ & $-0.81-0.22$ & $0.17(0.68)^{\#}$ & $-0.06-2.59$ & - & - & - & \\
\hline Age & $0.06(0.02)^{\#}$ & $0.00-0.08$ & $0.06(0.02)^{\#}$ & $0.00-0.08$ & $0.07(0.03)$ & $-0.01-0.10$ & $0.05(0.03)$ & $-0.03-0.09$ \\
\hline Marital status (married) & $-0.01(0.27)$ & $-0.58-0.48$ & $0.00(0.27)$ & $-0.54-0.52$ & $-0.03(0.37)$ & $-0.96-0.49$ & $0.03(0.40)$ & $-0.56-1.02$ \\
\hline Self-rated health (poor) & $0.10(0.46)^{\star \star}$ & $0.43-2.25$ & $0.11(0.47)^{\star \star}$ & $0.54-2.36$ & $0.08(0.71)^{\#}$ & $-0.22-2.58$ & $0.13(0.62)^{\star \star}$ & $0.40-2.85$ \\
\hline Depressive symptoms & $0.12(0.22)^{\star \star \star}$ & $0.33-1.17$ & $0.21(0.31)^{\star \star \star}$ & $0.69-1.89$ & $0.20(0.31)^{\star \star \star}$ & $0.72-1.93$ & $0.04(0.30)$ & $-0.39-0.81$ \\
\hline $\begin{array}{l}\text { Blacks } \times \text { depressive } \\
\text { symptoms }\end{array}$ & - & - & $-0.25(0.41)^{\star}$ & $-1.83-0.22$ & & & & \\
\hline
\end{tabular}

" $p<0.1$.

${ }^{*} p<0.05$.

${ }^{* *} p<0.01$

${ }_{* * *} p<0.001$.

symptoms, above and beyond all covariates $(\beta=0.11,95 \%$ $\mathrm{CI}=0.01-0.03)$. Model 2 showed a significant interaction between ethnicity and hopelessness on depressive symptoms ( $\beta=-0.27,95 \% \mathrm{CI}=-0.04$ to 0.00$)$, suggesting a stronger association for Whites compared to Blacks. This interaction was significant net of all covariates. Model 3 showed that hopelessness was associated with depressive symptoms among Whites $(\beta=0.19,95 \% \mathrm{CI}=0.02-0.04)$. Hopelessness was not associated with depressive symptoms among Blacks $(\beta=-0.02,95 \% \mathrm{CI}=-0.01$ to 0.03$)($ Model 4$)$. 
TABLE 4 | Summary of the linear regressions for the association between hopelessness (independent variable) and depressive symptoms (dependent variable) in the pooled sample and based on race.

\begin{tabular}{|c|c|c|c|c|c|c|c|c|}
\hline & $\beta$ (SE) & $95 \% \mathrm{Cl}$ & $\beta$ (SE) & $95 \% \mathrm{Cl}$ & $\beta$ (SE) & $95 \% \mathrm{Cl}$ & $\beta$ (SE) & $95 \% \mathrm{Cl}$ \\
\hline & \multicolumn{4}{|c|}{ All } & \multicolumn{2}{|c|}{ Whites } & \multicolumn{2}{|c|}{ Blacks } \\
\hline & \multicolumn{2}{|c|}{$\begin{array}{c}\text { Model } 1 \\
\text { Main effect }\end{array}$} & \multicolumn{2}{|c|}{$\begin{array}{c}\text { Model } 2 \\
\text { With interaction }\end{array}$} & \multicolumn{2}{|c|}{ Model 3} & \multicolumn{2}{|c|}{ Model 4} \\
\hline Race (Blacks) & $-0.01(0.04)$ & $-0.09-0.06$ & $0.24(0.14)^{\star}$ & $0.00-0.56$ & & & & \\
\hline Age & $-0.06(0.00)^{\#}$ & $-0.01-0.00$ & $-0.06(0.00)^{\#}$ & $-0.01-0.00$ & $-0.05(0.00)$ & $-0.01-0.00$ & $-0.05(0.00)$ & $-0.01-0.00$ \\
\hline Gender (female) & $0.04(0.04)$ & $-0.03-0.13$ & $0.04(0.04)$ & $-0.03-0.13$ & $0.03(0.05)$ & $-0.07-0.13$ & $0.06(0.07)$ & $-0.05-0.21$ \\
\hline $\begin{array}{l}\text { Education (graduated } \\
\text { from high school) }\end{array}$ & $-0.11(0.04)^{\star \star \star}$ & $-0.22-0.05$ & $-0.11(0.04)^{\star \star \star}$ & $-0.22-0.06$ & $-0.15(0.05)^{\star \star \star}$ & $-0.28-0.07$ & $-0.04(0.06)$ & $-0.18-0.07$ \\
\hline Marital status (married) & $-0.11(0.04)^{\star \star}$ & $-0.21-0.04$ & $-0.10(0.04)^{\star \star}$ & $-0.20-0.04$ & $-0.10(0.06)^{\star}$ & $-0.25-0.02$ & $-0.11(0.06)^{*}$ & $-0.25-0.02$ \\
\hline Self-rated health (poor) & $0.26(0.07)^{\star \star \star}$ & $0.43-0.70$ & $0.26(0.07)^{\star \star \star}$ & $0.43-0.70$ & $0.18(0.10)^{\star \star \star}$ & $0.22-0.63$ & $0.32(0.09)^{\star \star \star}$ & $0.48-0.85$ \\
\hline Hopelessness & $0.11(0.01)^{\star \star \star}$ & $0.01-0.03$ & $0.18(0.01)^{\star \star \star}$ & $0.01-0.04$ & $0.19(0.01)^{\star \star \star}$ & $0.02-0.04$ & $0.02(0.01)$ & $-0.01-0.03$ \\
\hline Blacks $\times$ hopelessness & & & $-0.27(0.01)^{\star}$ & $-0.04-0.00$ & & & & \\
\hline
\end{tabular}

" $p<0.1$.

${ }^{*} p<0.05$.

${ }^{* *} p<0.01$

${ }^{* * *} p<0.001$

\section{DISCUSSION}

Our study documented stronger reciprocal associations between depressive symptoms and hopelessness among Whites compared to Blacks. Our findings are in line with the differential effect hypothesis, which suggests ethnic groups differ for the associations that ultimately influence health and illness $(26,46-49)$. That is, ethnicity shapes the degree by which depressive symptoms accompany hopelessness in the general population of older adults.

We found a positive association between depressive symptoms and hopelessness in the pooled sample and Whites. Hopelessness positively correlates with depression (50-52) and suicidality (53) and negatively correlates with happiness (2) and appropriate adjustment in the presence of stress $(54,55)$. Hopelessness is a core feature in depressed individuals (1-6). Compared with individuals who are hopeless, those who maintain hope are more resilient when faced with stress (39). Hope serves as a motivational factor and helps with initiation and sustaining actions toward goals (56). In the context of clinical depression, hopelessness is a main determinant of suicidality (57), compliance, and treatment outcomes (58).

Our findings on the moderating effect of ethnicity on the depression-hopelessness link suggest that Beck's cognitive triad of depression may operate differently for sub-populations. Based on Beck's Cognitive Theory of Depression, negative cognitions about the future (hopelessness), as well as dysfunctional beliefs about self and the world, are core components of depression (2). Our study suggests that hoplessness accompanies depression differently across ethnic groups. Black-White differences were observed in the effects of depression on dysfunctional attitudes about self ${ }^{1,2}$. In two nationally representative studies using independent samples, Assari has documented a stronger effects of depression on self-esteem and self-evaluation among Blacks compared to Whites ${ }^{1}$. These studies have suggested that depression may leave a larger scar on self-perception for Blacks compared to Whites ${ }^{1}$.
Our findings on ethnic-specific attitudes about future (hopelessness) may inform how cognitive behavioral therapy and psychotherapy can benefit from tailoring based on ethnicity. Dysfunctional attitudes about future, self, and others are being considered as targets of psychotherapy of the illness (59). Ethnic groups, who differ in how depression changes attitudes about self, others, and future (60), may benefit differently from cognitive behavioral therapies with the same level of emphasis on attitudes about self, others, and future. Our results suggest that Blacks may need less emphasis on hope as a component of psychotherapy for depression, compared to Whites (61). Thus, current results are relevant to the program planning and clinical practice that aim to reduce ethnic inequalities in depression outcomes in the United States. Findings also inform how we should measure depression (as a latent factor) is composed of dysfunctional attitudes about future, self, and others, across ethnically diverse groups (62). This is particularly important because such dysfunctional attitudes are prognostic factors for the treatment of depression (63).

Although early theories of hope had conceptualized the construct as a unidimensional motivational force (28), more recent models have expanded how we define hope. In 1969, Stotland described hope as "an expectation greater than zero of achieving a goal" (29). In 1987, Scheier and Carver defined hope and optimism as the "tendency to believe that one will generally experience positive vs. negative outcomes in life" $(27,64)$. Snyder viewed hope as an "internal sense of success and an active motivation state" (3, $65,66)$. In Snyder's view, hope is composed of two interrelated cognitive dimensions: agency and pathways (3, 65-67). Agency and pathway components of hope have different implications regarding depression (28). In one study, the agency but not the pathway component of hope predicted later depression (28).

Our findings also suggest that the salience of hopelessness as a mechanism behind development and course of depression may vary across ethnic groups. According to the theory of hopelessness depression, "hopelessness temporally precedes depression and is 
a proximal sufficient cause of the symptoms of depression." Based on this theory, hopelessness explains the effects of stress and lack of social support on depression (68). Our findings suggest that the degree by which hopelessness contributes to depression is larger for Whites than Blacks (69). Whether or not the theory of hopelessness depression is differently valid for Blacks and Whites is still unknown.

Our findings on Black-White differences in the link between depressive symptoms and hopelessness are in line with other Black-White differences in other domains of health, which are linked with depression. Blacks and Whites differ in the links between stress, medical conditions, and depression $(14,49,70-72)$. Blacks and Whites also differ in the effect of baseline depressive symptoms on subsequent medical conditions and death $(3,14,24,73,74)$. These differential associations can be explained by our current finding that ethnicity mitigates the link between depressive symptoms and hope. The results also support Black-White paradox $(74,75)$, defined as a lower risk of depression among Blacks despite a higher risk of adversities including medical conditions $(14,71,76)$.

Our findings are not supported by the literature that suggests clinical depression is more consequential for Blacks compared to Whites $(14,77,78)$. Depression is believed to be more chronic and disabling for Blacks compared to Whites $(14,77,78)$. Higher prevalence of comorbid medical conditions $(79,80)$, somatic presentation of depression (81), lower access and trust to the health-care system combined with higher stigma $(14,77,78)$, as well as negative beliefs regarding pharmaceutical treatments $(14,82)$ make depression more consequential for Blacks compared to Whites $(14,83$, 84 ). Blacks have a lower chance of diagnosis and treatment of depression, and if they do receive a diagnosis, they will receive lower quality of services as they tend to get depression treatment in primary care settings rather than mental health-care settings $(78,85)$.

Our findings do not support the multiple disadvantage theory (86-88), which suggests the same risk factors are more harmful for Blacks than Whites, as they are exposed to multiple exposures (89). Our findings that depressive symptoms accompanied more hope for Blacks compared to Whites can be better understood in a resiliency framework (90). Despite a higher rate of poverty (91), lower social position (78), more severe depression (92), more comorbid conditions (78), less access to health care (72), and differences in the diagnosis and treatment of depression (93), Blacks with depression may have a higher tendency to maintain hope, possibly due to endorsing higher levels of religiosity and receiving higher levels of social support.

Our findings have major implications for clinical practice. Sense of hope is essential for maintaining self-efficacy (5), selfcare, health services use, and positive psychological outcomes (94). Compared to Whites, Blacks with depression see the future as more positive, a finding that may help clinicians who treat depression among diverse population groups. Hopelessness increases negative feelings and uncertain views about future events and possibilities (67) and reduces the expectation that positive outcomes may be forthcoming in the future $(3,66$,
95-97). These negative views may be more prevalent in depression among Whites than Blacks.

An implication of our finding is for suicide research and practice. Hopelessness strongly predicts suicide and may mediate the effect of depression on suicidality (98). Thus, our findings on higher hopefulness in the presence of depression may partially explain the lower suicide rate of Blacks compared to Whites $(46,99,100)$. According to our findings, suicide prevention programs among Whites who suffer depression may require more emphasis on hope enhancement (101).

Our study had a few limitations. The first limitation is the exploratory nature of our statistical analyses conducted. Second, validity of measures used to assess depressive symptoms and hopelessness may vary across ethnic groups (102). We did not use specific psychometric tools to assess hopelessness but simply adopted a four-item scale. We cannot rule out differential underreporting of depressive symptoms and hopelessness across ethnic groups $(81,103)$. We also did not measure stereotype threat. Blacks may express less hopelessness due to concerns regarding being negatively evaluated. Third, participants were either Christians or those who were never associated with any faith. Future research should test if ethnicity or faith explains Black-White differences in the link between depression and hopelessness. Finally, as we did not have longitudinal data and did not use path modeling for data analysis, we do not conclude any causation from observed associations. Thus, we do not argue that depression differently causes hopelessness across groups. Both empirical evidence and theoretical work have suggested that the links between depression and hopelessness are bidirectional. Based on the scar model, depression diminishes hope and according to the vulnerability model, hopelessness increases vulnerability for depression (4-6). Despite these limitations, our study is one of the first studies on ethnic heterogeneity of the association between depression and hopelessness. Using a national sample and considerable sample size of Blacks were the strengths of the current study.

Results of this study help us understand ethnic differences in correlates of depression. Hope is one of the most neglected virtues in the literature (104). Human virtues such as hope and optimism are strong buffers against psychological adversities on a wide range of mental disorders $(105,106)$.

More research is needed on possible roles that attitudes about self, others, and future play on depression across various ethnic groups (103). Future research may also explore how the current findings can be used to reduce the burden of depression and hopelessness across populations. Differential hopelessness may contribute to ethnic variation in causes, courses, and consequences of depression across ethnic groups, which have implications for the elimination of health disparities (107-111).

\section{CONCLUSION}

In summary, Black-White differences exist in the magnitude of the association between depressive symptoms and hopelessness, with Blacks showing a weaker association compared to Whites. This finding suggests that depression may be more hopeless for Whites compared to Blacks. 


\section{ETHICS STATEMENT}

All procedures followed were in accordance with the ethical standards of the responsible committee on human experimentation (institutional and national) with the Helsinki Declaration of 1975 , as revised in 2000. Informed consent was obtained from all participants included in the study.

\section{INFORMED CONSENT}

Informed consent was obtained from all participants included in the study.

\section{AUTHOR CONTRIBUTIONS}

SA designed and analyzed this work, and ML drafted and revised the paper. SA had full access to all of the data in the study and takes responsibility for the integrity of the data and the accuracy of the data analysis.

\section{REFERENCES}

1. Peleg G, Barak O, Harel Y, Rochberg J, Hoofien D. Hope, dispositional optimism and severity of depression following traumatic brain injury. Brain Inj (2009) 23(10):800-8. doi:10.1080/02699050903196696

2. Peterson C. The future of optimism. Am Psychologist (2000) 12:119-32.

3. Scheier MF, Carver CS. Optimism, coping, and health: assessment and implications of generalized outcome expectancies. Health Psychol (1985) 4:219-47. doi:10.1037/0278-6133.4.3.219

4. Chimich WT, Nekolaichuk CL. Exploring the links between depression, integrity, and hope in the elderly. Can J Psychiatry (2004) 49(7):428-33.

5. Farran CJ, Popovich JM. Hope: a relevant concept for geriatric psychiatry. Arch Psychiatr Nurs (1990) 4(2):124-30. doi:10.1016/0883-9417(90)90019-H

6. ChochinovHM. Thinkingoutsidethebox:depression, hope, andmeaning at the end of life. J Palliat Med (2003) 6(6):973-7. doi:10.1089/109662103322654893

7. Beck AT, Brown G, Berchick RJ, Stewart BL, Steer RA. Relationship between hopelessness and ultimate suicide: a replication with psychiatric outpatients. Am J Psychiatry (1990) 147:190-5. doi:10.1176/ajp.147.2.190

8. Beck AT, Weissman A, Lester D, Trexler L. The measurement of pessimism: the hopelessness scale. J Consult Clin Psychol (1974) 42:861-5. doi:10.1037/ h0037562

9. Brown GK, Beck AT, Steer RA, Grisham JR. Risk factors of suicide in psychiatric outpatients. JConsult Clin Psychol (2000) 68:371-7. doi:10.1037/0022-006X.68.3.371

10. Beevers CG, Miller IW. Perfectionism, cognitive bias, and hopelessness as prospective predictors of suicidal ideation. Suicide Life-Threat Behav (2004) 34:126-37. doi:10.1521/suli.34.2.126.32791

11. Tanaka E, Sakamoto S, Ono Y, Fujihara S, Kitamura T. Hopelessness in a community population: factorial structure and psychosocial correlates. J Soc Psychol (1998) 138:581-90. doi:10.1080/00224549809600413

12. Pompili M, Innamorati M, Gonda X, Serafini G, Sarno S, Erbuto D, et al. Affective temperaments and hopelessness as predictors of health and social functioning in mood disorder patients: a prospective follow-up study. J Affect Disord (2013) 150(2):216-22. doi:10.1016/j.jad.2013.03.026

13. Hirsch JK, Visser PL, Chang EC, Jeglic EL. Race and ethnic differences in hope and hopelessness as moderators of the association between depressive symptoms and suicidal behavior. J Am Coll Health (2012) 60(2):115-25. doi: 10.1080/07448481.2011.567402

14. Williams DR, González HM, Neighbors H, Nesse R, Abelson JM, Sweetman J, et al. Prevalence and distribution of major depressive disorder in African Americans, Caribbean Blacks, and Non-Hispanic Whites: results from the

\section{ACKNOWLEDGMENTS}

SA is supported by the Heinz C. Prechter Bipolar Research Fund and the Richard Tam Foundation at the University of Michigan Depression Center.

\section{FUNDING}

The religion, aging, and health survey was supported by the National Institute on Aging (R01 AG014749; PI: Neal Krause), and per the NIH Public Access Policy requires that peerreviewed research publications generated with NIH support are made available to the public through PubMed Central. $\mathrm{NIH}$ is not responsible for the data collection or analyses represented in this article. Data were accessed through The Interuniversity Consortium for Political and Social Research (ICPSR), the Institute of Social Research, University of Michigan.

National Survey of American Life. Arch Gen Psychiatry (2007) 64(3):305-15 doi:10.1001/archpsyc.64.3.305

15. Heinonen K, Raikkonen K, Matthews KA, Scheier MF, Raitakari OT, Pulkki $\mathrm{L}$, et al. Socioeconomic status in childhood and adulthood: associations with dispositional optimism and pessimism over a 21-year follow-up. J Pers (2006) 74:1111-26. doi:10.1111/j.1467-6494.2006.00404.x

16. Korkeila K, Kivela S, Suominen S, Vahtera J, Kivimaki M, Sundell J, et al. Childhood adversities, parent-child relationships and dispositional optimism in adulthood. Soc Psychiatry Psychiatr Epidemiol (2004) 39:286-92. doi:10.1007/s00127-004-0740-x

17. Shelby RA, Crespin TR, Wells-Di Gregorio SM, Lamdan RM, Siegel JE, Taylor KL. Optimism, social support, and adjustment in African American women with breast cancer. J Behav Med (2008) 31(5):433-44. doi:10.1007/ s10865-008-9167-2

18. Lankarani MM, Assari S. Association between number of comorbid medical conditions and depression among individuals with diabetes; race and ethnic variations. J Diabetes Metab Disord (2015) 7(14):56. doi:10.1186/ s40200-015-0171-0

19. Assari S, Lankarani MM. Association between stressful life events and depression; intersection of race and gender. J Racial Ethn Health Disparities (2015) 2(3):1-8. doi:10.1007/s40615-015-0160-5

20. Assari S. Race and ethnic differences in associations between cardiovascular diseases, anxiety, and depression in the United States. Int J Travel Med Glob Health (2014) 2(3):103-9.

21. Assari S. Association between obesity and depression among American Blacks: role of ethnicity and gender. J Racial Ethn Health Disparities (2014) 1:36-44. doi:10.1007/s40615-014-0007-5

22. Assari S. Additive effects of anxiety and depression on body mass index among Blacks: role of ethnicity and gender. Int Cardiovasc Res J (2014) 8(2):44-51.

23. Assari S. Separate and combined effects of anxiety, depression and problem drinking on subjective health among Black, Hispanic and Non-Hispanic White men. Int J Prev Med (2014) 5(3):269-79.

24. Assari S, Burgard S. Black-White differences in the effect of baseline depressive symptoms on deaths due to renal diseases: 25 year follow up of a nationally representative community sample. J Renal Inj Prev (2015) 4(4):127-34. doi:10.12861/jrip.2015.27

25. Assari S. Chronic medical conditions and major depressive disorder: differential role of positive religious coping among African Americans, Caribbean Blacks and Non-Hispanic Whites. Int J Prev Med (2014) 5(4):405-13 
26. Slopen N, Williams DR, Fitzmaurice GM, Gilman SE. Sex, stressful life events, and adult onset depression and alcohol dependence: are men and women equally vulnerable? Soc Sci Med (2011) 3(4):615-22. doi:10.1016/j. socscimed.2011.06.022

27. Zhang W, O'Brien N, Forrest JI, Salters KA, Patterson TL, Montaner JS, et al. Validating a shortened depression scale (10 item CES-D) among HIVpositive people in British Columbia, Canada. PLoS One (2012) 7:e40793. doi:10.1371/journal.pone.0040793

28. Arnau RC, Rosen DH, Finch JF, Rhudy JL, Fortunato VJ. Longitudinal effects of hope on depression and anxiety: a latent variable analysis. J Pers (2007) 75(1):43-64. doi:10.1111/j.1467-6494.2006.00432.x

29. Stotland E. The Psychology of Hope. San Francisco: Jossey-Bass (1969).

30. Boling TE. Black and White religion: a comparison in the lower class. Sociol Anal (1975) 36:73-80. doi:10.2307/3710198

31. Chatters LM, Taylor RJ, Bullard KM, Jackson JS. Spirituality and subjective religiosity among African Americans, Caribbean Blacks and Non-Hispanic Whites. J Sci Study Relig (2008) 47(4):725-37. doi:10.1111/j.1468-5906. 2008.00437.x

32. Taylor RJ, Chatters LM, Jackson JS. Religious and spiritual involvement among older African Americans, Caribbean Blacks, and Non-Hispanic Whites: findings from the National Survey of American Life. J Gerontol B Psychol Sci Soc Sci (2007) 62(4):S238-50. doi:10.1093/geronb/62.4.S238

33. Krause N, Hayward RD. Religious music and health in late life: a longitudinal investigation. Int J Psychol Relig (2014) 24(1):47-63. doi:10.1080/10508619. 2012.761529

34. Haley WE, West CA, Wadley VG, Ford GR, White FA, Barrett JJ, et al. Psychological, social, and health impact of caregiving: a comparison of Black and White dementia family caregivers and noncaregivers. Psychol Aging (1995) 10(4):540-52. doi:10.1037/0882-7974.10.4.540

35. Krause N. Religion, Aging, and Health Survey, 2001, 2004 [United States]. ICPSR03255- $v 2$. Ann Arbor, MI: Inter-University Consortium for Political and Social Research [distributor] (2006). Available from: http://doi. org/10.3886/ICPSR03255.v2

36. Radloff LS. The CES-D scale: a self-report depression scale for research in the general population. Appl Psychol Meas (1977) 1:385-401. doi:10.1177/ 014662167700100306

37. Turvey CL, Wallace RB, Herzog R. A revised CES-D measure of depressive symptoms and a DSM-based measure of major depressive episodes in the elderly. Int Psychogeriatr (1999) 11(02):139-48. doi:10.1017/ S1041610299005694

38. Van de Velde S, Levecque K, Bracke P. Measurement equivalence of the CES-D 8 in the general population in Belgium: a gender perspective. Arch Public Health (2009) 67(1):15. doi:10.1186/0778-7367-67-1-15

39. Amtmann D, Kim J, Chung H, Bamer AM, Askew RL, Wu S, et al. Comparing CESD-10, PHQ-9, and PROMIS depression instruments in individuals with multiple sclerosis. Rehabil Psychol (2014) 59:220-9. doi:10.1037/a0035919

40. Andresen EM, Malmgren JA, Carter WB, Patrick DL. Screening for depression in well older adults: evaluation of a short form of the CES-D (center for epidemiologic studies depression scale). Am J Prev Med (1994) 10:77-84.

41. Krause N. A comprehensive strategy for developing closed-ended survey items for use in studies of older adults. J Gerontol B Psychol Sci Soc Sci (2002) 57:S263-74. doi:10.1093/geronb/57.5.S263

42. Krause N. God-mediated control and change in self-rated health. Int J Psychol Relig (2010) 20(4):267-87. doi:10.1080/10508619.2010.507695

43. Vuorisalmi M, Lintonen T, Jylhä M. Global self-rated health data from a longitudinal study predicted mortality better than comparative self-rated health in old age. JClin Epidemiol (2005) 58(7):680-7. doi:10.1016/j. jclinepi.2004.11.025

44. Sargent-Cox KA, Anstey KJ, Luszcz MA. The choice of self-rated health measures matter when predicting mortality: evidence from 10 years follow-up of the Australian longitudinal study of ageing. BMC Geriatr (2010) 10:18. doi:10.1186/1471-2318-10-18

45. Vuorisalmi M, Lintonen T, Jylhä M. Comparative vs global self-rated health: associations with age and functional ability. Aging Clin Exp Res (2006) 18(3):211-7. doi:10.1007/BF03324651

46. Assari S, Lankarani MM, Moazen B. Religious beliefs may reduce the negative effect of psychiatric disorders on age of onset of suicidal ideation among Blacks in the United States. Int J Prev Med (2012) 3(5):358-64.
47. Assari S, Moghani Lankarani M, Moghani Lankarani R. Ethnicity modifies the effects of anxiety and drug use on suicidal ideation among Black adults in the United States. Int J Prev Med (2013) 4(11):1251-7.

48. Assari S. Race and ethnicity, religion involvement, church-based social support and subjective health in United States: a case of moderated mediation. Int J Prev Med (2013) 4(2):208-17.

49. Assari S, Smith JR, Caldwell CH, Zimmerman MA. Gender differences in longitudinal links between neighborhood fear, parental support, and depression among African American emerging adults. Societies (2015) 5(1):151-70. doi:10.3390/soc5010151

50. Chang EC. A critical appraisal and extension of hope theory in middle aged men and women: is it important to distinguish agency and pathways components? J Soc Clin Psychol (2003) 22:121-43. doi:10.1521/jscp.22.2.121 22876

51. Elliott TR, Witty TE, Herrick S, Hoffman JT. Negotiating reality after physical loss: hope, depression, and disability. J Pers Soc Psychol (1991) 61:608-13. doi:10.1037/0022-3514.61.4.608

52. Kwon P. Hope and dysphoria: the moderating role of defense mechanisms. J Personal (2000) 68:199-223. doi:10.1111/1467-6494.00095

53. Range LM, Penton SR. Hope, hopelessness, and suicidality in college students. Psychol Rep (1994) 75:456-8. doi:10.2466/pr0.1994.75.1.456

54. Jackson WT, Taylor RE, Palmatier AD, Elliott TR, Elliott JL. Negotiating the reality of visual impairment: hope, coping, and functional ability. J Clin Psychol Med Settings (1998) 5:173-85. doi:10.102 3/A:1026259115029

55. Cramer KM, Dyrkacz L. Differential prediction of maladjustment scores with the Snyder hope subscales. Psychol Rep (1998) 83:1035-41. doi:10.2466/ PR0.83.7.1035-1041

56. Ciarrochi J, Parker P, Kashdan TB, Heaven PC, Barkus E. Hope and emotional well-being: a six-year study to distinguish antecedents, correlates, and consequences. J Posit Psychol (2015) 10(6):520-32. doi:10.1080/17439760.2 015.1015154

57. Rudd MD, Joiner TE, Rajab MH. Treating Suicidal Behavior: an Effective, Time-Limited Approach. New York: Guilford Press (2004).

58. Alavi A, Sharifi B, Ghanizadeh A, Dehbozorgi G. Effectiveness of cognitive-behavioral therapy in decreasing suicidal ideation and hopelessness of the adolescents with previous suicidal attempts. Iran J Pediatr (2013) 23(4):467-72.

59. Beck AT, Rush AJ, Shaw BF, Emery G. Cognitive Therapy of Depression. New York: The Guilford Press (1979). 11 p.

60. Kwon SM, Oei TP. Cognitive change processes in a group cognitive behavior therapy of depression. J Behav Ther Exp Psychiatry (2003) 34(1):73-85. doi:10.1016/S0005-7916(03)00021-1

61. Sadeghi H, Ebrahimi L, Vatandoust L. Effectiveness of hope therapy protocol on depression and hope in amphetamine users. Int J High Risk Behav Addict (2015) 4(4):e21905. doi:10.5812/ijhrba.21905

62. Rogers GM, Park JH, Essex MJ, Klein MH, Silva SG, Hoyle RH, et al. The dysfunctional attitudes scale: psychometric properties in depressed adolescents. J Clin Child Adolesc Psychol (2009) 38(6):781-9. doi:10.1080/15374410903259007

63. Shankman SA, Campbell ML, Klein DN, Leon AC, Arnow BA, Manber $\mathrm{R}$, et al. Dysfunctional attitudes as a moderator of pharmacotherapy and psychotherapy for chronic depression. J Psychiatr Res (2013) 47(1):113-21. doi:10.1016/j.jpsychires.2012.09.018

64. Scheier MF, Carver CS. Dispositional optimism and physical well-being: the influence of generalized expectancies on health. J Pers (1987) 55:169-210. doi:10.1111/j.1467-6494.1987.tb00434.x

65. Snyder CR. Conceptualizing, measuring, and nurturing hope. J Counsel Dev (1995) 73(3):355-60. doi:10.1002/j.1556-6676.1995.tb01764.x

66. Snyder CR. Hope theory: rainbows in the mind. Psychol Inq (2002) 13:249-75. doi:10.1207/S15327965PLI1304_01

67. Snyder CR, Shorey HS, Cheavens J, Pulvers KM, Adams VH III, Wiklund C. Hope and academic success in college. J Educ Psychol (2002) 94(4):820-6. doi:10.1037/0022-0663.94.4.820

68. Abramson LY, Metalsky GI, Alloy LB. Hopelessness depression: a theory-based subtype of depression. Psychol Rev (1989) 96(2):358-72. doi:10.1037/0033-295X.96.2.358 
69. Beck AT, Riskind JH, Brown G, Steer RA. Levels of hopelessness in DSM-III disorders: a partial test of content-specificity in depression. Cognit Ther Res (1988) 12:459-69. doi:10.1007/BF01173413

70. Assari S, Watkins DC, Caldwell CH. Race attribution modifies the association between daily discrimination and major depressive disorder among Blacks: the role of gender and ethnicity. J Racial Ethn Health Disparities (2015) 2(2):200-10. doi:10.1007/s40615-014-0064-9

71. Vines AI, Ta M, Esserman D, Baird DD. A comparison of the occurrence and perceived stress of major life events in Black and White women. Women Health (2009) 49(5):368-80. doi:10.1080/03630240903238743

72. Brown LJP, Powell J, Earls F. Stressful life events and psychiatric symptoms in Black adolescent females. JAdolesc Res (1989) 4(2):140-51. doi: $10.1177 / 074355488942004$

73. Assari S, Moazen-Zadeh E, Lankarani MM, Micol-Foster V. Race, Depressive Symptoms, and All-Cause Mortality in the United States. Front Public Health (2016) 4:40. doi:10.3389/fpubh.2016.00040

74. Keyes CL. The Black-White paradox in health: flourishing in the face of social inequality and discrimination. JPers (2009) 77(6):1677-706. doi:10.1111/j.1467-6494.2009.00597.x

75. Assari S, Burgard S, Zivin K. Long-term reciprocal associations between depressive symptoms and number of chronic medical conditions: longitudinal support for Black-White health paradox. J Racial Ethn Health Disparities (2015) 2(4):589-97. doi:10.1007/s40615-015-0116-9

76. Assari S, Sonnega A, Pepin R, Leggett A. Residual effects of restless sleep over depressive symptoms on chronic medical conditions: race by cender differences. J Racial Ethn Health Disparities (2016) 2:589-97. doi:10.1007/ s40615-015-0202-z

77. Gonzalez HM, Tarraf W. Comorbid cardiovascular disease and major depression among ethnic and racial groups in the United States. Int Psychogeriatr (2013) 25(5):833-41. doi:10.1017/S1041610212002062

78. Watkins DC, Assari S, Johnson-Lawrence V. Race and ethnic group differences in comorbid major depressive disorder, generalized anxiety disorder, and chronic medical conditions. J Racial Ethn Health Disparities (2015) 2(3):385-94. doi:10.1007/s40615-015-0085-Z

79. Cabassa LJ, Humensky J, Druss B, Lewis-Fernández R, Gomes AP, Wang S, et al. Do race, ethnicity, and psychiatric diagnoses matter in the prevalence of multiple chronic medical conditions? Med Care (2013) 51(6):540-7. doi:10.1097/MLR.0b013e31828dbb19

80. Kessler RC, Gruber M, Hettema JM, Hwang I, Sampson N, Yonkers KA. Co-morbid major depression and generalized anxiety disorders in the National Comorbidity Survey follow-up. Psychol Med (2008) 38(3):365-74. doi:10.1017/S0033291707002012

81. Bailey RK, Blackmon HL, Stevens FL. Major depressive disorder in the African American population: meeting the challenges of stigma, misdiagnosis, and treatment disparities. J Natl Med Assoc (2009) 101(11):1084-9. doi:10.1016/S0027-9684(15)31102-0

82. Jackson JS, Knight KM. Race and self-regulatory health behaviors: the role of the stress response and the HPA axis in physical and mental health disparities. In: Schaie KW, Carstensen LL, editors. Social Structures, Aging, and Self-Regulation in the Elderly. New York: Springer (2006). p. 189-207.

83. Bell C, Williamson J, Chien P. Cultural, racial and ethnic competence and psychiatric diagnosis. Ethn Inequal Health Soc Care (2008) 1(1):34-41. doi:10.1108/17570980200800006

84. Williams DR, Haile R, González HM, Neighbors H, Baser R, Jackson JS. The mental health of Black Caribbean immigrants: results from the national survey of American life. Am J Public Health (2007) 97(1):52-9. doi:10.2105/ AJPH.2006.088211

85. Agyemang AA, Mezuk B, Perrin P, Rybarczyk B. Quality of depression treatment in Black Americans with major depression and comorbid medical illness. Gen Hosp Psychiatry (2014) 36(4):431-6. doi:10.1016/j. genhosppsych.2014.02.011

86. Ferraro KF, Kelley-Moore JA. Cumulative disadvantage and health: longterm consequences of obesity? Am Sociol Rev (2003) 68(5):707. doi:10.2307/ 1519759

87. Grollman EA. Multiple disadvantaged statuses and health the role of multiple forms of discrimination. J Health Soc Behav (2014) 55(1):3-19. doi:10.1177/0022146514521215
88. Dale D. Cumulative advantage/disadvantage and the life course: cross-fertilizing age and social science theory. J Gerontol B Psychol Sci Soc Sci (2003) 58(6):S327-37. doi:10.1093/geronb/58.6.S327

89. Wee HL, Li SC, Cheung YB, Fong KY, Thumboo J. The influence of ethnicity on health-related quality of life in diabetes mellitus: a population-based, multiethnic study. J Diabetes Complications (2006) 20(3):170-8. doi:10.1016/j. jdiacomp.2005.06.010

90. Bonanno GA. Loss, trauma, and human resilience: have we underestimated the human capacity to thrive after extremely aversive events? Am Psychol (2004) 59(1):20-8. doi:10.1037/0003-066X.59.1.20

91. Malat J, Oh HJ, Hamilton MA. Poverty experience, race, and child health. Public Health Rep (2005) 120(4):442-7.

92. Fisher L, Laurencin G, Chesla CA, Skaff MM, Mullan JT, Gardiner PS, et al. Depressive affect among four with type 2 diabetes. Diabetes Spectr (2004) 17(4):215-24. doi:10.2337/diaspect.17.4.215

93. Anderson GM, Grumbach K, Loft HS, Roos LL, Mustard C, Brook R. Use of coronary artery bypass surgery in the United States and Canada: influence of age and income. J Am Med Assoc (1993) 269:1661-6. doi:10.1001/ jama.269.13.1661

94. Hong W, Abela JR, Cohen JR, Sheshko DM, Shi XT, Hamel AV, et al. Rumination as a vulnerability factor to depression in adolescents in mainland China: lifetime history of clinically significant depressive episodes. J Clin Child Adolesc Psychol (2010) 39(6):849-57. doi:10.1080/15374416.2010.51 7159

95. Sanna LJ. Defensive pessimism, optimism, and stimulating alternatives: some ups and downs of prefactual and counterfactual thinking. JPers Soc Psychol (1996) 71(5):1020. doi:10.1037/0022-3514.71.5.1020

96. Sun H, Tan Q, Fan G, Tsui Q. Different effects of rumination on depression: key role of hope. Int J Ment Health Syst (2014) 8:53. doi:10.1186/17524458-8-53

97. Greenaway KH, Frye M, Cruwys T. When aspirations exceed expectations: quixotic hope increases depression among students. PLoS One (2015) 10(9):e0135477. doi:10.1371/journal.pone.0135477

98. Chochinov HM, Wilson KG, Enns M, Lander S. Depression, hopelessness, and suicidal ideation in the terminally ill. Psychosomatics (1998) 39(4):36670. doi:10.1016/S0033-3182(98)71325-8

99. Assari S. Ethnic and gender differences in additive effects of socio-economics, psychiatric disorders, and subjective religiosity on suicidal ideation among Blacks. Int J Prev Med (2015) 6:53. doi: $10.4103 / 2008-7802.158913$

100. Assari S. Synergistic effects of lifetime psychiatric disorders on suicidal ideation among Blacks in the USA.J Racial Ethn Health Disparities (2014) 1(4):275-82. doi:10.1007/s40615-014-0034-2

101. Frew PM, Omer SB, Parker K, Bolton M, Schamel J, Shapiro E, et al. Delivering a "dose of hope": a faith-based program to increase older African Americans' participation in clinical trials. JMIR Res Protoc (2015) 4(2):e64. doi:10.2196/ resprot.4072

102. Boardman JD, Alexander KB. Stress trajectories, health behaviors, and the mental health of Black and White young adults. Soc Sci Med (2011) 72(10):1659-66. doi:10.1016/j.socscimed.2011.03.024

103. Ward E, Mengesha M. Depression in African American men: a review of what we know and where we need to go from here. Am J Orthopsychiatry (2013) 83(203):386-97. doi:10.1111/ajop.12015

104. Seligman MEP. Positive social science. APA Monit (1998) 29:2.

105. Farran CJ, Herth KA, Popovich JM. Hope and Hopelessness: Critical Clinical Constructs. Thousand Oaks, CA: SAGE (1995).

106. Seligman MEP, Csikszentmihalyi M. Positive psychology: an introduction. Am Psychol (2000) 55:5-14. doi:10.1037/0003-066X.55.1.5

107. Takeuchi DT, Zane N, Hong S, Chae DH, Gong F, Gee GC, et al. Immigrationrelated factors and mental disorder among Asian Americans. Am J Public Health (2007) 97:84-90. doi:10.2105/AJPH.2006.088401

108. Latkin CA, Curry AD, Hua W, Davey MA. Direct and indirect associations of neighborhood disorder with drug use and high-risk sexual partners. Am J Prev Med (2007) 32(6 Suppl):S234-41. doi:10.1016/j. amepre.2007.02.023

109. Kessler RC, Berglund P, Demler O, Jin R, Merikangas KR, Walters EE. Lifetime prevalence and age-of-onset distributions of DSM-IV disorders 
in the National Comorbidity Survey Replication. Arch Gen Psychol (2005) 62:593-602. doi:10.1001/archpsyc.62.6.617

110. Kessler RC, Chiu WT, Demler O, Walters EE. Prevalence, severity, and comorbidity of 12 month DSM-IV disorders in the National Comorbidity Survey Replication. Arch Gen Psychol (2005) 62:617-27. doi:10.1001/ archpsyc.62.6.617

111. Assari S, Moazen-Zadeh E. Ethnic variation in the cross-sectional association between domains of depressive symptoms and clinical depression. Front. Psychiat (2016) 7(53):1-10. doi:10.3389/ fpsyt.2016.00053
Conflict of Interest Statement: The authors declare that the research was conducted in the absence of any commercial or financial relationships that could be construed as a potential conflict of interest.

Copyright $\odot 2016$ Assari and Lankarani. This is an open-access article distributed under the terms of the Creative Commons Attribution License (CC BY). The use, distribution or reproduction in other forums is permitted, provided the original author(s) or licensor are credited and that the original publication in this journal is cited, in accordance with accepted academic practice. No use, distribution or reproduction is permitted which does not comply with these terms. 